\title{
High Density Lipoprotein Protects Mesenchymal Stem Cells from Oxidative Stress-Induced Apoptosis via Activation of the PI3K/Akt Pathway and Suppression of Reactive Oxygen Species
}

\author{
Jianfeng Xu ${ }^{1,2,3}$, Juying Qian ${ }^{1}{ }^{*}$, Xinxing Xie ${ }^{1}$, Li Lin ${ }^{1}$, Yunzeng Zou ${ }^{1,2}$, Mingqiang Fu ${ }^{1}$, \\ Zheyong Huang ${ }^{1}$, Guoping Zhang ${ }^{2}$, Yangang Su ${ }^{1}$ and Junbo Ge ${ }^{1,2, *}$
}

1 Department of Cardiology, Zhongshan Hospital, Fudan University, Shanghai Institute of Cardiovascular Diseases, Shanghai 200032, China; E-Mails: doctorxjf@126.com (J.X.); novaxie@163.com (X.X.); linli777@126.com (L.L.); zou.yunzeng@zs-hospital.sh.cn (Y.Z.); barkfmq@yahoo.com.cn (M.F.); huang.zheyong@zs-hospital.sh.cn (Z.H.); su.yangang@zs-hospital.sh.cn (Y.S.)

2 Institutes of Biomedical Scienses, Fudan University, Shanghai 200032, China; E-Mail: gpzhang@fudan.edu.cn

3 Department of Cardiology, Minhang Hospital, Ruijin Hospital Group, Shanghai Jiaotong University School of Medicine, Shanghai 201199, China

* Authors to whom correspondence should be addressed;

E-Mails: qian.juying@zs-hospital.sh.cn (J.Q.); ge.junbo2@zs-hospital.sh.cn (J.G.);

Tel.: +86-21-6404-1990 (J.Q. \& J.G.); Fax: +86-21-6422-3006 (J.Q. \& J.G.).

Received: 26 September 2012; in revised form: 11 November 2012 / Accepted: 4 December 2012 / Published: 13 December 2012

Abstract: The therapeutic effect of transplantation of mesenchymal stem cells (MSCs) in myocardial infarction (MI) appears to be limited by poor cell viability in the injured tissue, which is a consequence of oxidative stress and pro-apoptotic factors. High density lipoprotein (HDL) reverses cholesterol transport and has anti-oxidative and anti-apoptotic properties. We, therefore, investigated whether HDL could protect MSCs from oxidative stress-induced apoptosis. MSCs derived from the bone marrow of rats were pre-incubated with or without HDL, and then were exposed to hydrogen peroxide $\left(\mathrm{H}_{2} \mathrm{O}_{2}\right)$ in vitro, or were transplanted into experimentally infarcted hearts of rats in vivo. Pre-incubation of MSCs with HDL increased cell viability, reduced apoptotic indices and resulted in parallel decreases in reactive oxygen species (ROS) in comparison with control MSCs. Each of the beneficial effects of HDL on MSCs was attenuated by inhibiting the PI3K/Akt pathway. Preconditioning with HDL resulted in higher MSC survival rates, improved cardiac 
remodeling and better myocardial function than in the MSC control group. Collectively, these results suggest that HDL may protect against $\mathrm{H}_{2} \mathrm{O}_{2}$-induced apoptosis in MSCs through activation of a PI3K/Akt pathway, and by suppressing the production of ROS.

Keywords: high density lipoprotein; mesenchymal stem cells; oxidative stress; apoptosis; myocardial infarction

\section{Introduction}

An increasing number of studies have described transplantation of mesenchymal stem cells (MSCs) from bone marrow as a strategy for cardiac repair following myocardial infarction [1]. However, the therapeutic efficacy of this procedure is greatly limited by the poor survival of donor MSCs in the infarcted heart [2]. The injured myocardium represents an environment in which there are various factors that promote cell apoptosis, such as oxidative stress, hypoxia and inflammatory reactions [3]. Oxidative stress has been shown to be one of the key pro-apoptotic factors as it is present in both the ischemic stage and also during the reperfusion period [4,5]. Oxidative stress results in excessive accumulation of reactive oxygen species (ROS), which directly damages cell membranes, protein and DNA, thereby promoting cell senescence, compromising cell function and threatening cell survival $[4,6]$. Enhancing the viability of implanted MSCs and restoring cellular repair mechanisms are therefore critical factors in obtaining satisfactory outcomes with MSC-based therapy.

It is widely reported that high density lipoprotein (HDL) lowers the risks associated with ischemic cardiovascular diseases [7]. HDL has been reported to possess a variety of novel and functional properties in addition to its ability to reverse cholesterol transport (RCT) [8]. We have previously demonstrated that HDL abrogates cardiac hypertrophy induced by angiotensin II by down-regulating the expression of angiotensin II type 1 (AT-1) receptors [9]. Other workers have shown that the effects of experimentally induced ROS in the vascular wall were completely abolished by a daily infusion of reconstituted HDL [10]. HDL has also been shown to protect endothelial cells from primary apoptosis, and to reduce intracellular ROS induced by oxidized low-density lipoproteins [11]. These data suggested that HDL might have anti-oxidative and anti-apoptotic effects in cardiovascular pathophysiology.

We, therefore, investigated whether HDL could protect MSCs against oxidative stress-induced apoptosis. Additionally, we also examine the effect of HDL on the MSCs senescence, which was regarded to be induced by oxidative stress and to influence cell therapeutic potential considerably. Previously, the effects of HDL on endothelial progenitor cells [12], embryonic stem cells [13], hematopoietic stem cells [14] and induced pluripotent stem cells [13] have been reported, but to date there are no data describing the influence of HDL in the biological activity of MSCs. In the present study, we testified the impact of preconditioning with HDL on MSCs apoptosis and senescence induced by oxidative stress. In addition, hydrogen peroxide $\left(\mathrm{H}_{2} \mathrm{O}_{2}\right)$, which is widely used as an oxidant $[4,15]$, was applied in vitro to induce a form of cellular damage similar to oxidative stress. 


\section{Results and Discussion}

\subsection{HDL Protects MSCs against $\mathrm{H}_{2} \mathrm{O}_{2}$-Induced Apoptosis}

To investigate the effect of HDL on the biological activity of MSCs, we performed flow cytometry and MTS to detect cell differentiation and cell viability respectively. We observed that the MSCs (Passage 4), used in our experiments, expressed typical MSC-related cell surface antigens, which were positive for CD29, CD90 and negative for CD45, CD34; and that the incubation with HDL $(100 \mu \mathrm{g} / \mathrm{mL})$ for $24 \mathrm{~h}$ did not exhibit a notably impact on the characteristic phenotypes of MSCs (Figure S1). Meanwhile, we discovered that MSCs viability was not significantly affected by treatment with any of the tested concentrations of HDL (Figure 1A). Therefore, we chose a HDL concentration of $100 \mu \mathrm{g} / \mathrm{mL}$ for subsequent experiments based on methods described in previously published studies [9].

Figure 1. Effects of $\mathrm{H}_{2} \mathrm{O}_{2}$ and/or high density lipoprotein (HDL) on mesenchymal stem cell (MSC) viability and apoptosis. (A, B) MSCs were exposed to increasing concentrations of $\mathrm{HDL}(0$ to $200 \mu \mathrm{g} / \mathrm{mL})$ or $\mathrm{H}_{2} \mathrm{O}_{2}(0$ to $500 \mu \mathrm{M})$ for $24 \mathrm{~h}$; and cell viability was measured by MTS assay; (A) HDL did not significantly affect MSC viability; (B) $\mathrm{H}_{2} \mathrm{O}_{2}$ decreased the viability of MSCs in a concentration-dependent manner; (C to E) Cells were incubated with $\mathrm{H}_{2} \mathrm{O}_{2}(400 \mu \mathrm{M})$ following preconditioning with or without HDL $(100 \mu \mathrm{g} / \mathrm{mL})$ for $24 \mathrm{~h}$. Cell apoptosis was measured by TUNEL and caspase-3 assays as shown in photomicrograph $\mathbf{C}$ (scale bar $=20 \mu \mathrm{m}$ ) and in histogram $\mathbf{D}$ respectively. MSC viability (E) was measured by MTS assay. Results were confirmed in three, independent experiments. $* p<0.05$ vs. Control, $* * p<0.01$ vs. Control; $\# p<0.05$ vs. $\mathrm{H}_{2} \mathrm{O}_{2}$ group.
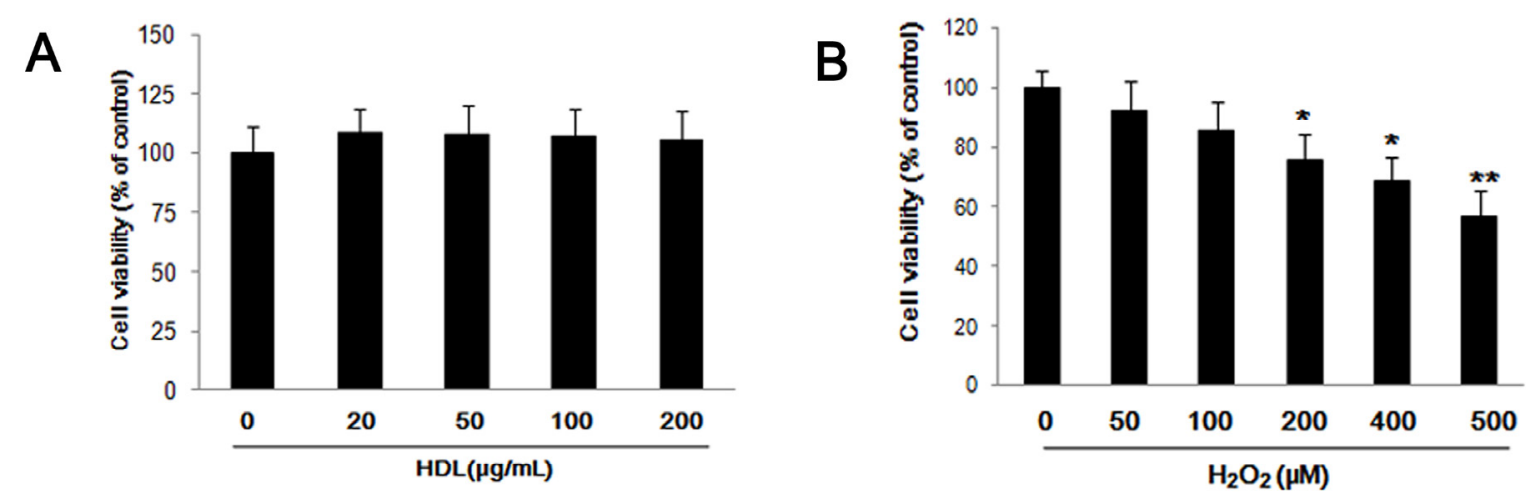

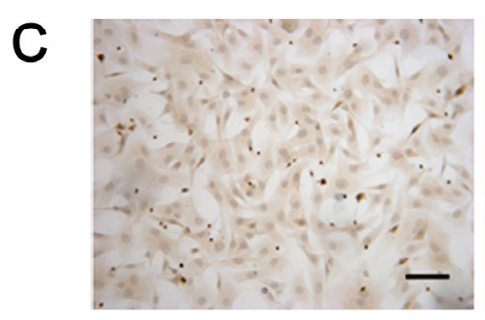

Control

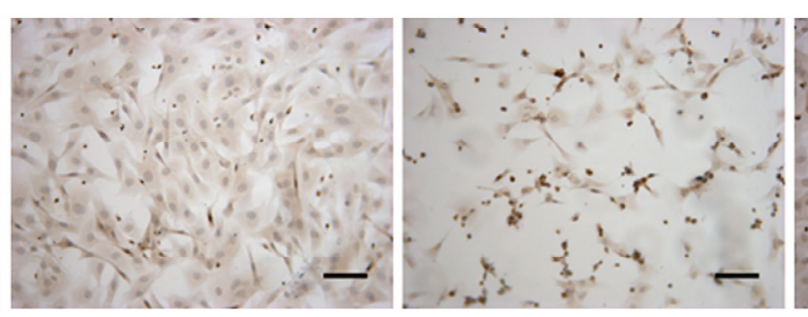

HDL
$\mathrm{H}_{2} \mathrm{O}_{2}$

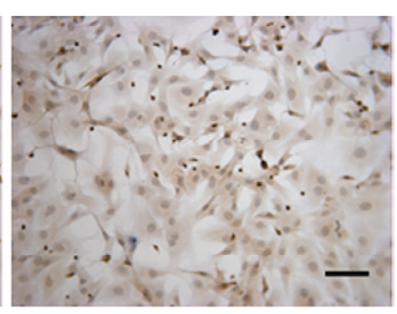

$\mathrm{HDL}+\mathrm{H}_{2} \mathrm{O}_{2}$ 
Figure 1. Cont.
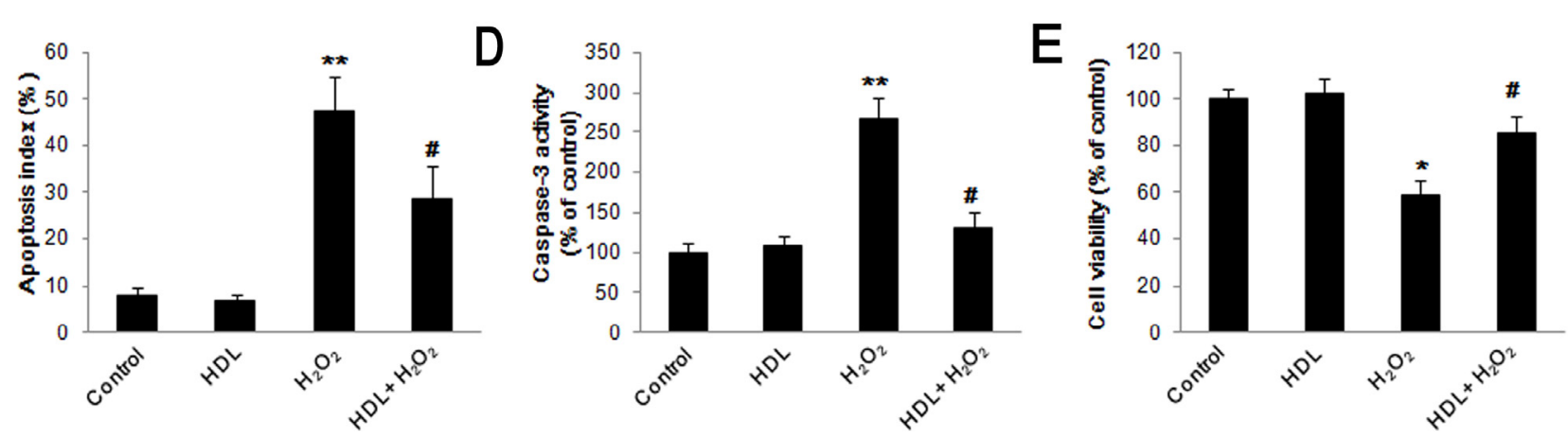

To determine the concentration of $\mathrm{H}_{2} \mathrm{O}_{2}$, which was employed to induce the cell apoptosis, MSCs was cultured with different concentration of $\mathrm{H}_{2} \mathrm{O}_{2}$ for $24 \mathrm{~h}$ and a MTS assay was performed afterwards. It was found that $\mathrm{H}_{2} \mathrm{O}_{2}$ impaired the viability of MSCs in a concentration-dependent manner over the tested concentration range (Figure 1B). The effect was statistically significant at concentrations over $200 \mu \mathrm{M}$. Based on these findings, $400 \mu \mathrm{M} \mathrm{H}_{2} \mathrm{O}_{2}$ was selected for use in the subsequent experiments.

In order to investigate the effects of $\mathrm{HDL}$ on $\mathrm{H}_{2} \mathrm{O}_{2}$-stimulated MSC apoptosis, MSCs were pretreated with or without HDL $(100 \mu \mathrm{g} / \mathrm{mL})$ for $24 \mathrm{~h}$ and then cultured with $400 \mu \mathrm{M}$ of $\mathrm{H}_{2} \mathrm{O}_{2}$ for an additional $24 \mathrm{~h}$. TUNEL assay showed that incubation with $100 \mu \mathrm{g} / \mathrm{mL}$ HDL did not affect the apoptosis of MSCs (HDL group vs. Control group: $(6.83 \pm 1.35) \%$ vs. $(7.93 \pm 1.76) \%, p>0.05)$. However, $\mathrm{H}_{2} \mathrm{O}_{2}$ significantly increased MSCs apoptosis $\left(\mathrm{H}_{2} \mathrm{O}_{2}\right.$ group vs. Control group: $(47.37 \pm 7.53) \%$ vs. $(7.93 \pm 1.76) \%, p<0.01)$, which was remarkably attenuated after preconditioning with $\mathrm{HDL}\left(\mathrm{HDL}+\mathrm{H}_{2} \mathrm{O}_{2}\right.$ group vs. $\mathrm{H}_{2} \mathrm{O}_{2}$ group: $(28.77 \pm 6.91) \%$ vs. $\left.(47.37 \pm 7.53) \%, p<0.05\right)$ (Figure 1C). Caspase-3 activity was significantly increased in $\mathrm{H}_{2} \mathrm{O}_{2}$-stimulated MSCs compared to controls $((267.4 \pm 25.3) \%$ vs. $(100 \pm 12.2) \%, p<0.01)$. The increased caspase-3 activity was ameliorated by pre-incubation with $\mathrm{HDL}\left(\mathrm{HDL}+\mathrm{H}_{2} \mathrm{O}_{2}\right.$ group $v s . \mathrm{H}_{2} \mathrm{O}_{2}$ group: $(130.9 \pm 19.7) \%$ vs. $(267.4 \pm 25.3) \%, p<0.05)$ (Figure 1D). Similarly, compared to $\mathrm{H}_{2} \mathrm{O}_{2}$ group, HDL pretreatment restored cell viability following exposure to $\mathrm{H}_{2} \mathrm{O}_{2}$ ( $\mathrm{HDL}+\mathrm{H}_{2} \mathrm{O}_{2}$ group vs. $\mathrm{H}_{2} \mathrm{O}_{2}$ group: $(85.3 \pm 7.2) \%$ vs. $(58.6 \pm 6.8) \%, p<0.05)$ (Figure $1 \mathrm{E})$.

Meanwhile, MSCs aging or senescence, which directly impaired the regenerative capability, was widely reported to be induced by oxidative stress $[16,17]$. We, therefore, wondered whether HDL treatment could protect MSCs against $\mathrm{H}_{2} \mathrm{O}_{2}$-stimulated replicative exhaustion. Senescence-associated $\beta$-Galactosidase (SA- $\beta$-Gal) staining showed that there were no significant differences in the percentages of SA- $\beta$-Gal positive cells between the HDL group and the Control group $((102.3 \pm 13.7) \% v s .(100 \pm 12.4) \%, p>0.05)$. Similarly, there was nearly identical in those between the $\mathrm{H}_{2} \mathrm{O}_{2}$ group and the HDL $+\mathrm{H}_{2} \mathrm{O}_{2}$ group $((356.2 \pm 25.8) \%$ vs. $(367.9 \pm 22.37) \%, p>0.05)$, although there was a significant increment compared the $\mathrm{H}_{2} \mathrm{O}_{2}$ group with the Control one $(p<0.05)$ (Figure 2A). Furthermore, the MSCs senescence was confirmed by Western blot assay, suggesting that there were no remarkably differences in the expression of $\mathrm{p} 16^{\mathrm{INK} 4 \mathrm{a}}$ between the HDL group and the Control $((1.06 \pm 0.13) v s$. $(1.00 \pm 0.10), p>0.05)$, and between the $\mathrm{H}_{2} \mathrm{O}_{2}$ group and the $\mathrm{HDL}+\mathrm{H}_{2} \mathrm{O}_{2}$ group $((3.62 \pm 0.19) v s .(3.40 \pm 0.26), p>0.05)$. Likewise, it was found that the expression of $\mathrm{p} 16^{\mathrm{INK} 4 \mathrm{a}}$ in the $\mathrm{H}_{2} \mathrm{O}_{2}$ group statistically increased than that in the Control one $(p<0.05)$ (Figure 2B). Therefore, 
it indicated that HDL exerted no statistical effects on the senescence of MSCs both under a condition of oxidative stress and under that of control.

Figure 2. Influence of HDL in the MSC senescence. MSCs were treated with or without $\mathrm{HDL}$ for $24 \mathrm{~h}$ followed by exposure to $\mathrm{H}_{2} \mathrm{O}_{2}$ insult for another $24 \mathrm{~h}$ or not; (A) Senescence-associated $\beta$-Galactosidase staining and representative photograms from three independent experiments are displayed (scale bar $=20 \mu \mathrm{m})$; $(\mathbf{B})$ The expressions of p $16^{\mathrm{INK} 4 \mathrm{a}}$ were detected by Western blot analysis and representative bands are shown. Data are shown as mean $\pm \mathrm{SE}$ from three independent experiments. ${ }^{*} p<0.05 v s$. Control group, $n s$., not significant; GAPDH, glyceraldehyde 3-phosphate dehydrogenase.

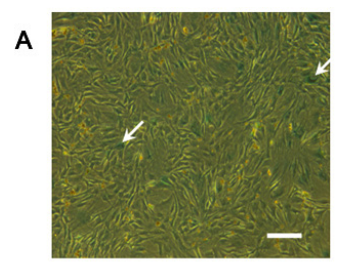

Control

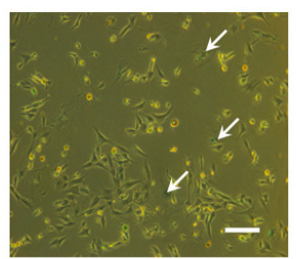

$\mathrm{H}_{2} \mathrm{O}_{2}$

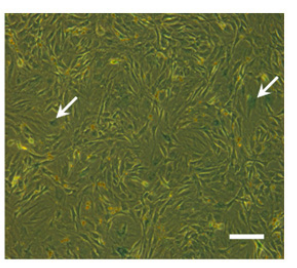

HDL

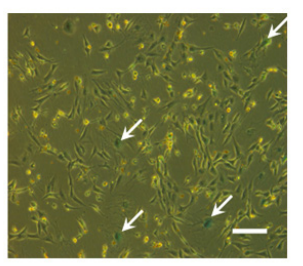

$\mathrm{HDL}+\mathrm{H}_{2} \mathrm{O}_{2}$

B

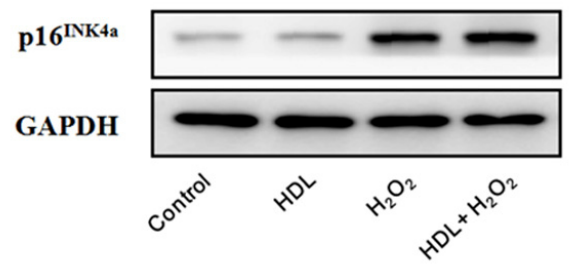

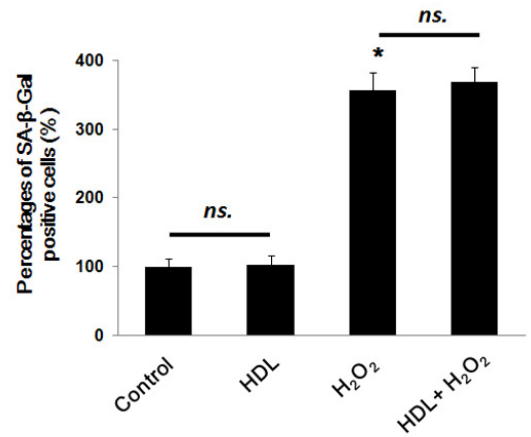

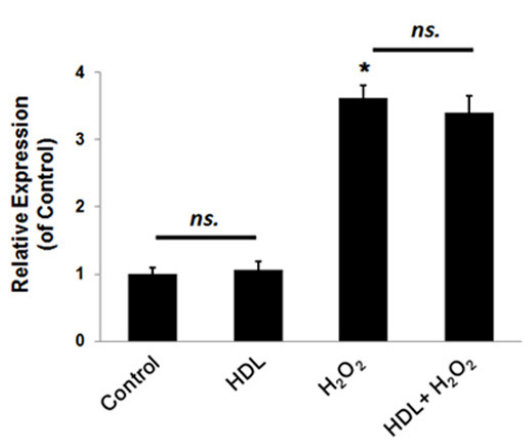

\subsection{PI3K/Akt Pathway Involves in the Protective Effect of $H D L$}

As previously reported [18], PI3K/Akt pathway played a critical role in the cell apoptosis. To examine our hypothesis that PI3K/Akt pathway was involved in the protective effect of HDL on MSCs, Western blot analysis was used to assess the changes in Akt phosphorylation in MSCs exposed to HDL with different concentration. The results indicated that incubation with HDL significantly up-regulated Akt phosphorylation. This response began $15 \mathrm{~min}$ after exposure, peaked at approximately $30 \mathrm{~min}$ (30-min group vs. Control group: $(283.8 \pm 25.1) \%$ vs. $(100 \pm 24.71) \%, p<0.05)$ and was still present at $24 \mathrm{~h}$ (24-h group vs. Control group: $(197.5 \pm 19.37) \%$ vs. $(100 \pm 24.71) \%$, $p<0.05$ ) (Figure 3A), suggesting that HDL could enhance the activation of PI3K/Akt pathway in MSCs. To provide further evidence, a PI3K inhibitor, LY294002, was effectively employed to decrease Akt activation (LY294002 group vs. Control group: $(12.37 \pm 5.19) \%$ vs. $(100 \pm 24.28) \%$, $p<0.05$ ) (Figure 3B). Considering that high concentrations of LY294002 could cause a reduction in 
cell viability or a generation of ROS, a LY294002 group was added to examine its toxicity to MSCs. It was observed that LY294002, at a concentration of $25 \mu \mathrm{M}$, did not exhibit a statistical effect on the MSCs viability (LY294002 group vs. Control group: $(97.6 \pm 6.8) \%$ vs. $(100 \pm 5.1) \%, p>0.05)$ (Figure 3C) and apoptosis (LY294002 group vs. Control group: $(106.4 \pm 13.5) \%$ vs. $(100 \pm 11.3) \%$, $p>0.05$ ) (Figure 3D), which was consistent with what was testified previously [19]. Intriguingly, the pre-treatment of LY294002 at this concentration was found to abolish the protective effect of $\mathrm{HDL}$ on $\mathrm{H}_{2} \mathrm{O}_{2}$-stimulated cells. This resulted in decreased cell viability as measured by MTS assay ( $\mathrm{HDL}+\mathrm{H}_{2} \mathrm{O}_{2}+\mathrm{LY} 294002$ group vs. $\mathrm{HDL}+\mathrm{H}_{2} \mathrm{O}_{2}+$ DMSO group: $(51.7 \pm 7.1) \%$ vs. (83.6 \pm 7.8$) \%$, $p<0.05$ ) (Figure 3C) and increased apoptosis estimated by changes in caspase-3 activity (HDL $+\mathrm{H}_{2} \mathrm{O}_{2}+\mathrm{LY} 294002$ group vs. $\mathrm{HDL}+\mathrm{H}_{2} \mathrm{O}_{2}+$ DMSO group: $(286.3 \pm 16.7) \%$ vs. $(149.5 \pm 21.8) \%, p<0.05)$ (Figure 3D), consistently indicating that HDL protected MSCs against injury induced by $\mathrm{H}_{2} \mathrm{O}_{2}$ through $\mathrm{PI} 3 \mathrm{~K} / \mathrm{Akt}$ pathway.

Figure 3. Role of PI3K/Akt pathway in the HDL induced anti-apoptotic protection. (A) Western blot analysis show that HDL significantly increased Akt phosphorylation in MSCs. (B to D) MSCs were pre-incubated with LY294002 $(25 \mu \mathrm{M})$ or DMSO for $1 \mathrm{~h}$ and then exposed to HDL $(100 \mu \mathrm{g} / \mathrm{mL})$ followed by exposure to $\mathrm{H}_{2} \mathrm{O}_{2}(400 \mu \mathrm{M})$ for a further $24 \mathrm{~h}$. Western blotting results show that Akt phosphorylation induced by HDL was decreased by pre-incubation with LY294002. The protective effect of HDL evidenced by cell viability and caspase-3 activity was significantly abolished by LY294002. Results were confirmed in three, independent experiments. $* p<0.05$ vs. Control, $* * p<0.01$ vs. Control, and $p<0.05$ vs. $\mathrm{H}_{2} \mathrm{O}_{2}$ group, $\S p<0.05$ vs. $\mathrm{HDL}+\mathrm{H}_{2} \mathrm{O}_{2}+$ DMSO group, $n s$, not significant; DMSO, Dimethyl sulfoxide.
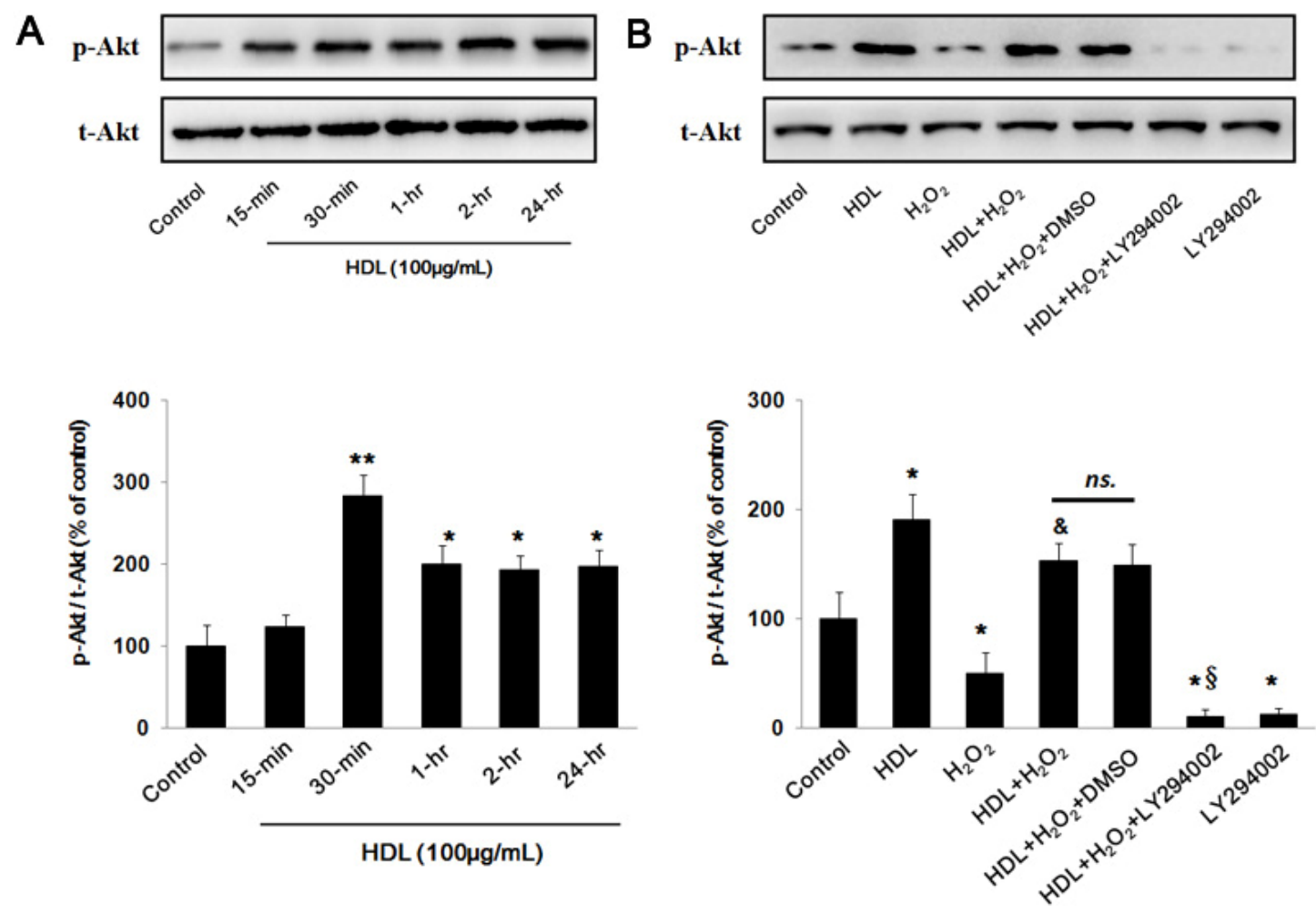
Figure 3. Cont.

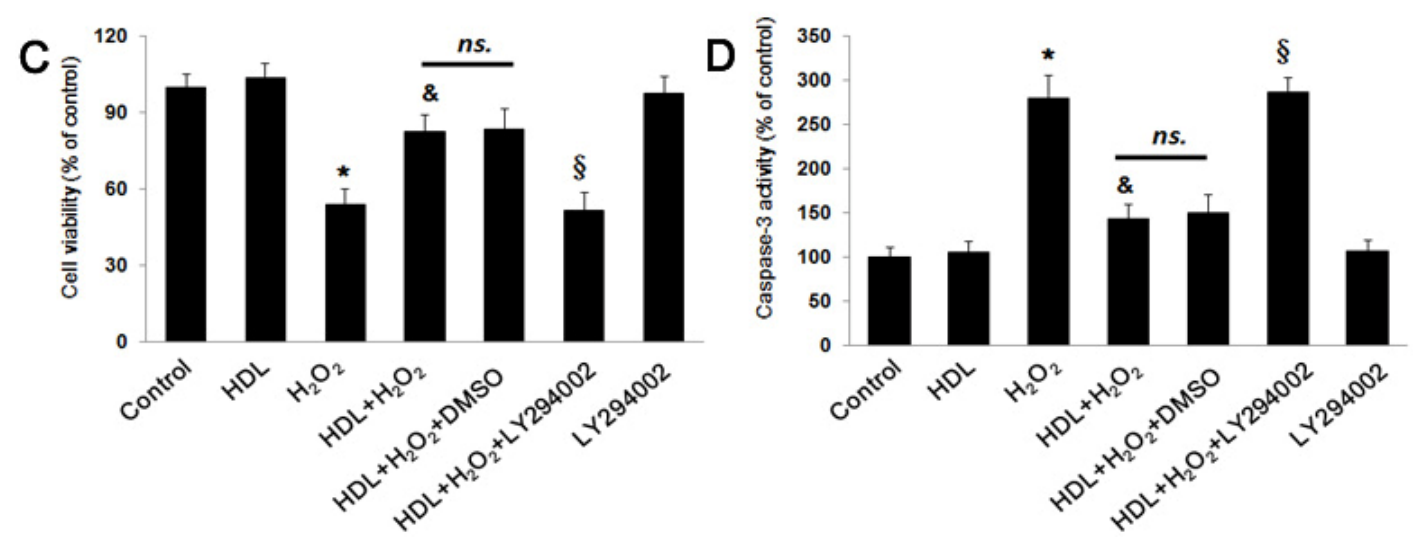

\subsection{Phosphorylation of Akt Induced by HDL Inhibits ROS Generation}

The influence of the PI3K/Akt pathway in ROS production based on LY294002 inhibition and assessed using fluorescent probe-DHE demonstrated that the percentage of ROS negative cells with low fluorescence intensity were similarly observed among the Control, the HDL and the LY294002 groups (all $p>0.05$ ) (Figure 4). Cells with strong red fluorescent, indicating ROS accumulation, were more prevalent in the $\mathrm{H}_{2} \mathrm{O}_{2}$ group than in the Control one $((435 \pm 48) \%$ vs. $(100 \pm 15) \%, p<0.05)$. HDL pretreatment restored intracellular ROS generation induced by $\mathrm{H}_{2} \mathrm{O}_{2}\left(\mathrm{HDL}+\mathrm{H}_{2} \mathrm{O}_{2}\right.$ group vs. $\mathrm{H}_{2} \mathrm{O}_{2}$ group: $(156 \pm 25) \%$ vs. $\left.(435 \pm 48) \%, p<0.05\right)$, and the protective effect disappeared when the PI3K/Akt pathway was inhibited by LY294002 ( HDL $+\mathrm{H}_{2} \mathrm{O}_{2}+$ DMSO group vs. $\mathrm{HDL}+\mathrm{H}_{2} \mathrm{O}_{2}+\mathrm{LY} 294002$ group: $(172 \pm 37) \%$ vs. $\left.(482 \pm 57) \%, p<0.01\right)$.

Figure 4. Impact of activation of PI3K/Akt pathway induced by HDL on reactive oxygen species (ROS) generation. The intracellular ROS in MSCs was visualized by fluorescent microscopy. Representative photomicrographs (scale bar $=100 \mu \mathrm{m}$ ) and corresponding histograms are displayed. Preconditioning with $\mathrm{HDL}$ inhibited $\mathrm{H}_{2} \mathrm{O}_{2}$-stimulated ROS generation in MSCs. However, the protective effect disappeared with LY294002 pretreatment. Results were confirmed in three independent experiments. ${ }^{*} p<0.05$ vs. Control group, \# $p<0.05$ vs. $\mathrm{H}_{2} \mathrm{O}_{2}$ group, $\$ p<0.05$ vs. $\mathrm{HDL}+\mathrm{H}_{2} \mathrm{O}_{2}+$ DMSO group, $n s$., not significant; DMSO, Dimethyl sulfoxide.

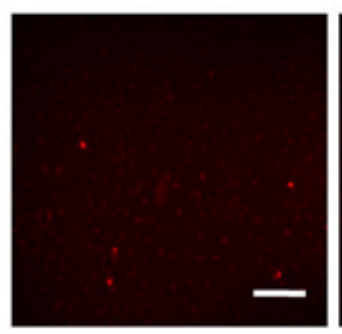

Control

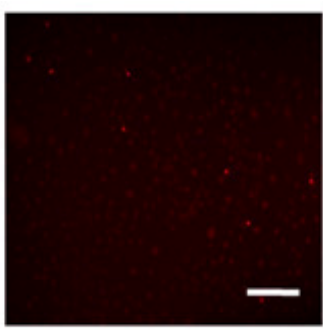

HDL

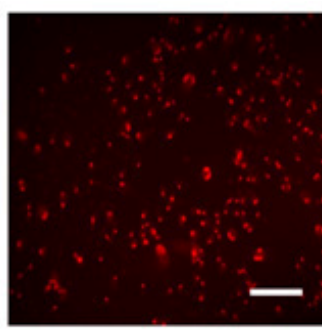

$\mathrm{H}_{2} \mathrm{O}_{2}$

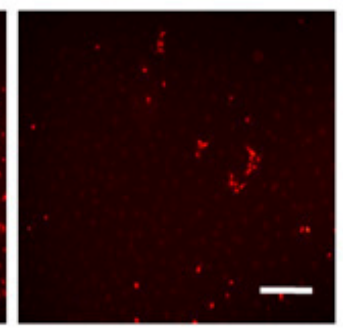

$\mathrm{HDL}+\mathrm{H}_{2} \mathrm{O}_{2}$ 
Figure 4. Cont.

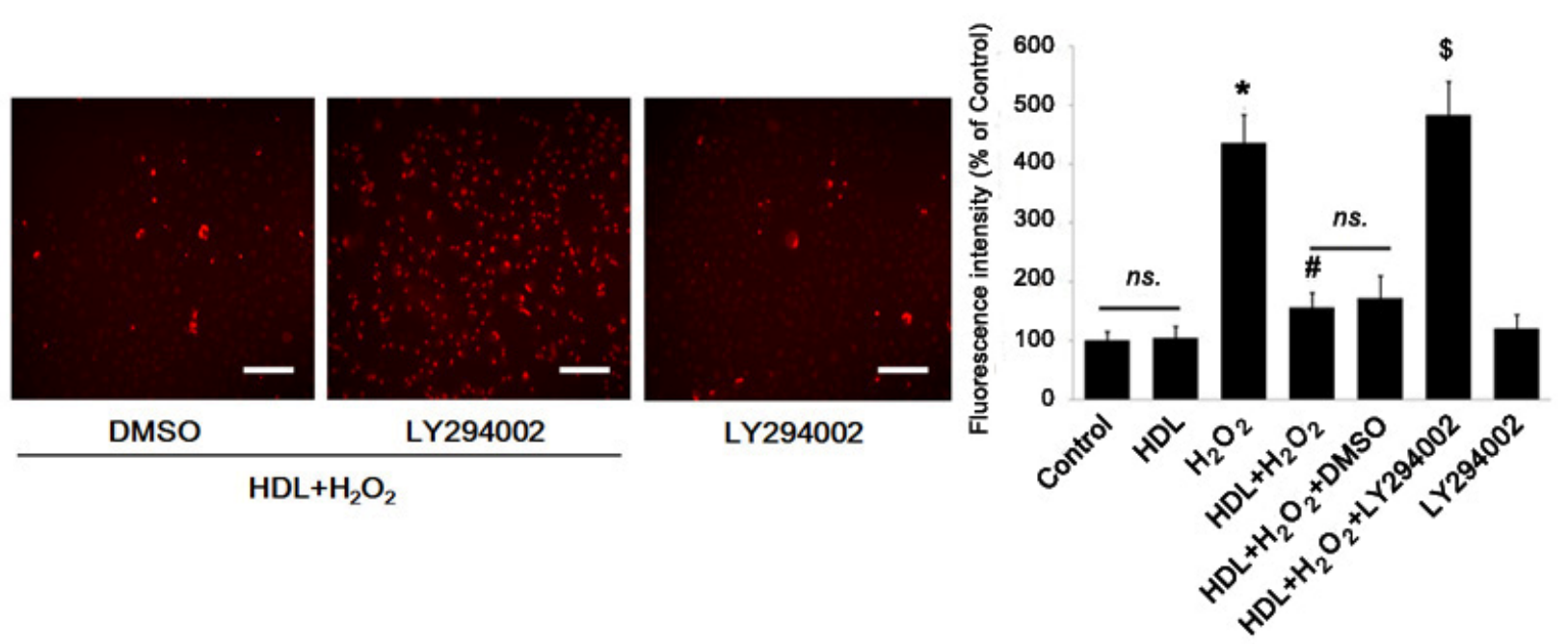

The above results showed that the inhibition of PI3K/Akt pathway attenuated the protective effect of HDL and the decreased ROS, indicating that Akt activation was partly upstream of ROS generation. Excessive production of ROS has been shown to damage stem cells through caspase-mediated pathways [20]. Therefore, these findings suggested that HDL activation of the PI3K/Akt pathway might inhibit ROS generation, and thereby reduce apoptosis of implanted MSCs.

\subsection{HDL Pre-Incubation Promotes MSC Survival in the Infarcted Heart}

The poor viability of the donor cell, typically $<1 \%$ at 4 days after transplantation, has been reported in the previous study regarding MSCs-base therapy [5]. Therefore, we testified the effect of HDL preconditioning on the survival of MSCs on Day 4 after transplantation in vivo (Figure 5A,B). After a GFP-labeling and the pre-incubation with or without $\operatorname{HDL}(100 \mu \mathrm{g} / \mathrm{mL})$, MSCs $\left(1 \times 10^{6}\right.$ in $\left.100 \mu \mathrm{L}\right)$ were respectively transplanted into the infarcted heart of rats. It was discovered that the number of $\mathrm{GFP}^{+}$MSCs per HP in the HDL-MSCs group was 2.58-fold greater than that in the MSCs group $(p<0.05)$. Furthermore, when we transplanted the male MSCs to the female hearts, it was revealed that the sry DNA level in the HDL-MSCs group was approximately 2.83-fold higher than that in the MSCs group $(p<0.05)$, indicating that HDL preconditioning could enhance the survival of MSCs after transplantation.

\subsection{MSCs Preconditioned with HDL Reduce Cardiac Remodeling and Preserve Myocardial Function}

The effect of MSCs preconditioned with HDL on cardiac function was observed by transthoracic echocardiography four weeks after experimentally induced MI in rats (Figure 5C,D). It indicated that left ventricular ejection fraction (LVEF) was 50.8\% lower in the PBS group than in the Sham group and LVFS was 53.0\% lower in the PBS group than in the Sham group (both $p<0.05$ ); and that LVIDd was $40.9 \%$ higher and LVIDs was $90.0 \%$ higher in the PBS than in the Sham group (both $p<0.05$ ). Furthermore, compared with PBS group, transplantation of MSCs improved LVEF and LVFS by $13.0 \%$ and $21.6 \%$, respectively (both $p<0.05$ ). Injection of HDL-MSCs enhanced the LVEF and 
LVFS by an additional $13.0 \%$ and $20.1 \%$, respectively (both $p<0.05$ ). Transplantation of MSCs decreased the LVIDd and LVIDs by $19.5 \%$ and $23.3 \%$, respectively compared to the PBS group (both $p<0.05$ ), and transplantation of HDL-MSCs further decreased LVIDd and LVIDs by approximately $12.3 \%$ and $30.0 \%$ (both $p<0.05$ ), respectively.

Figure 5. Effects of HDL preconditioning on transplanted MSCs survival and cardiac function in the rats with experimental MI. (A and B) The number of $\mathrm{GFP}^{+}$MCSs was counted under fluorescent microscopy four days after injection. Representative photomicrographs $(\mathbf{A}$, scale bar $=100 \mu \mathrm{m})$ and the corresponding histogram are displayed. Male sry DNA was examined by real-time PCR. $n=7$ per group. ${ }^{*} p<0.05$ vs. MSCs group. (C and D) four weeks after therapeutic intervention, transthoracic echocardiography was performed to evaluate cardiac remodeling and LV function. Representative M-mode echocardiograms and quantitative data are shown. $n=8$ per group. ${ }^{*} p<0.05$ vs. PBS group, $\# p<0.05$ vs. MSCs group.

A
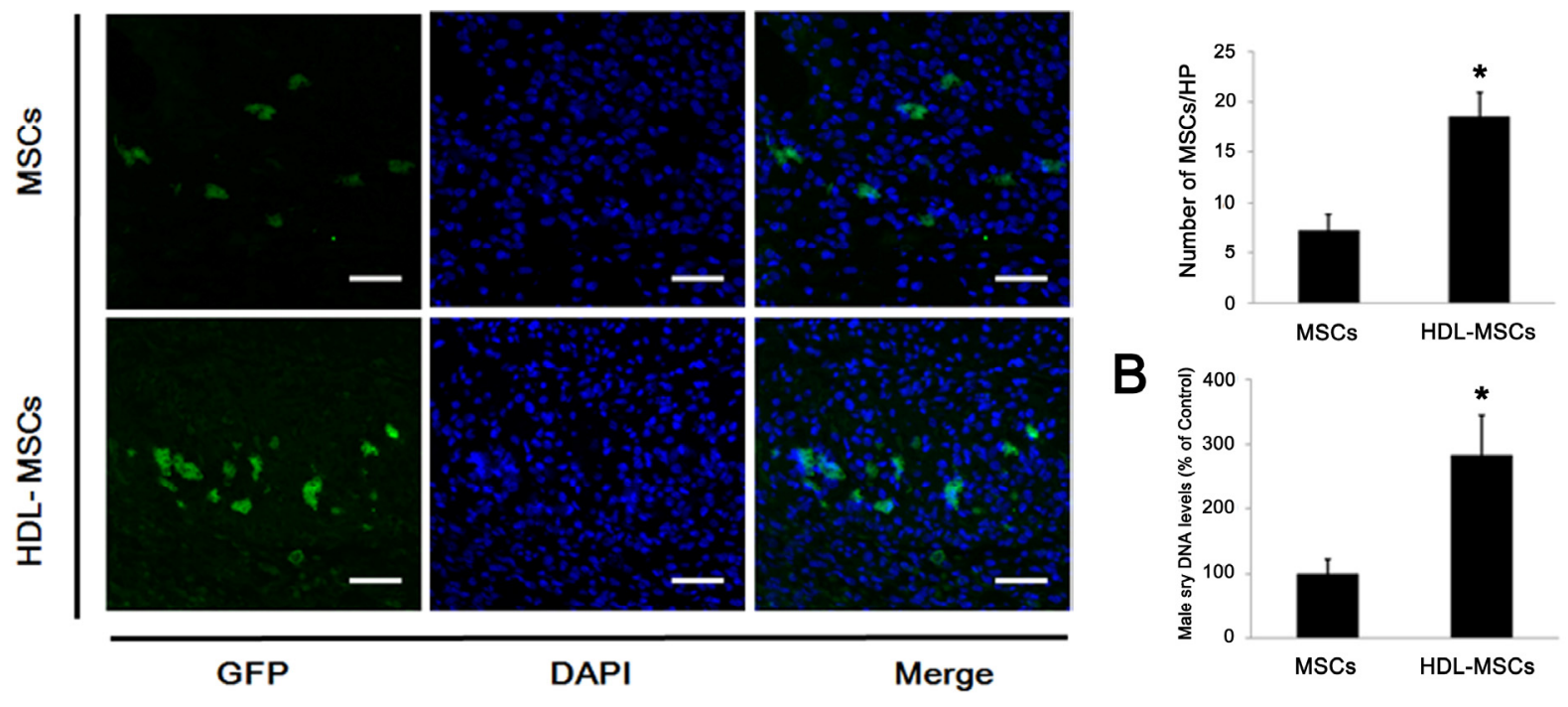

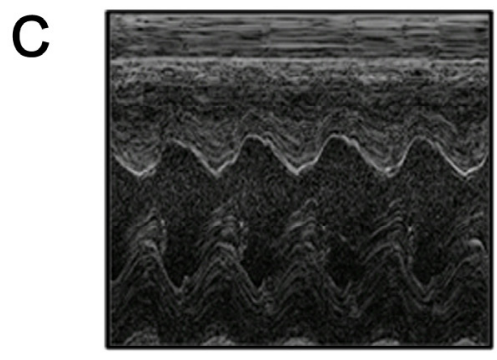

Sham

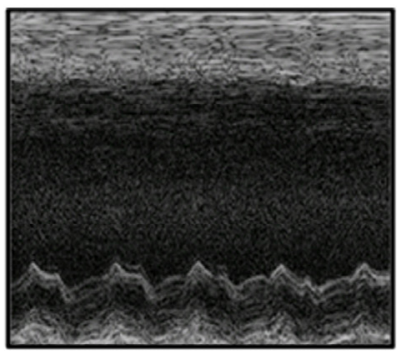

PBS

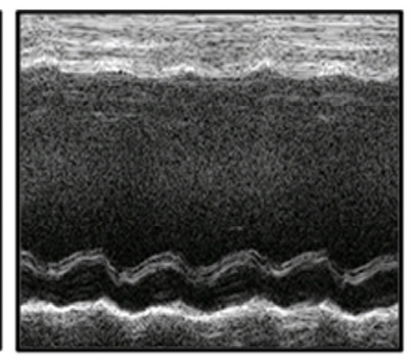

MSCs

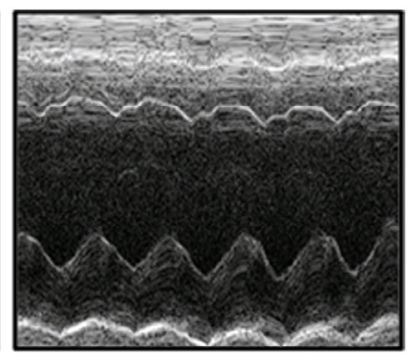

HDL-MSCs

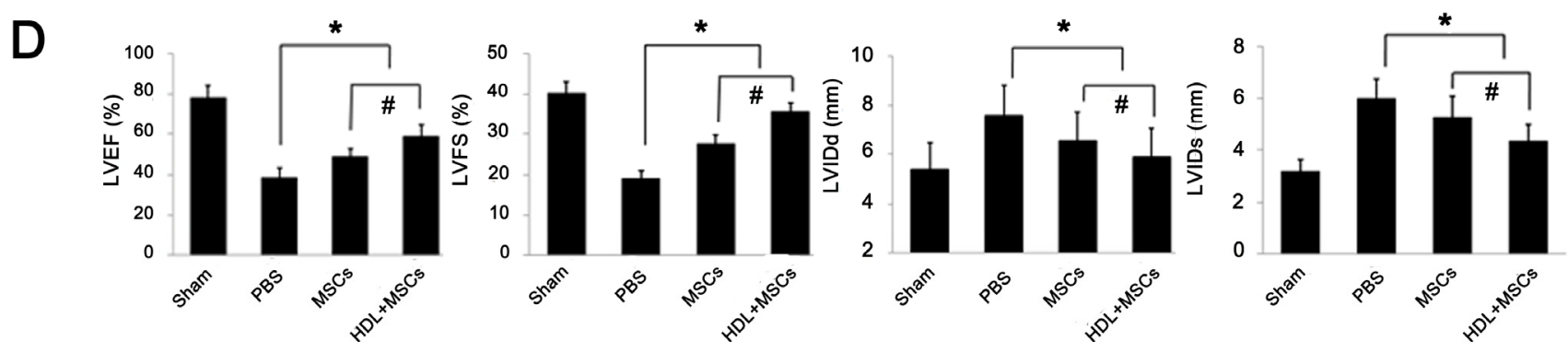


We noticed that Kiya Y et al. [21] had previously reported that continual infusion of HDL following MI prevented LV remodeling and improved myocardial function in rats. Though they attributed the better prognosis to an improvement of the survival of cardiomyocytes resulting from treatment with HDL, they had not well explored the influence of HDL on the cells that migrated to injured myocardium, such as MSCs. And our results from the present study might partly provided the evidences on a novel perspective to support their finding as follows: a higher level of HDL might improve the anti-apoptotic capability of MSCs, which were mobilized to the damaged myocardial region, thus contributing to the myocardial regeneration, bringing about a better cardiac function after MI.

In the recent literature, the effect of transplantation of MSCs on myocardial repair was reported as confined for the low viability of graft cells [1,22]. For instance, even $6 \times 10^{7}$ implanted MSCs in infarcted porcine hearts yielded only limited enhancement of LVEF [23]. A series of pharmacological preconditioning was thought to be an effective approach for promoting MSCs survival [24] but had the potential to cause severe side effects in patients with cardiovascular diseases.

Therefore, we explored whether improving the in-situ physiological environment of MSCs could enhance cells viability and prevent oxidative stress-induced apoptosis after transplantation or mobilization. Epidemiological studies have consistently shown an inverse correlation between HDL levels and outcomes in ischemic heart diseases [8]. We endeavored to elucidate this correlation with a hypothesis that HDL might promote survival of implanted MSCs, ameliorate their capacity to repair damaged tissue and thereby improve clinical prognosis. In support of this hypothesis, our data indicated that HDL protected MSCs from apoptosis induced by $\mathrm{H}_{2} \mathrm{O}_{2}$ in vitro. The mechanisms involved activation of PI3K/Akt pathway, which was consistent with findings from previously reported studies [15,22]. We also demonstrated that the anti-apoptotic effect of HDL enhanced survival of MSCs and improved myocardial repair in vivo, supporting the findings of previous researches showing that the administration of HDL preserved the post-ischemic cardiac function [25].

Beside apoptosis, cellular senescence had been proved to be the other main outcome following oxidative stress stimuli [16], which considerably impaired MSCs therapeutical properties. On the other hand, there were several literature suggesting that a higher level of HDL was associated with a slower rate of leukocyte telomere length shortening per year [26]; and that offspring of individuals with exceptional longevity had significantly larger HDL, which hinted that HDL was probably involved in the cellular aging [27]. Considering those evidences, we carried out the parallel experiments to investigate whether HDL could play a critical role in the protective effect on MSCs senescence stimulated by oxidative stress. $\mathrm{H}_{2} \mathrm{O}_{2}$ treatment expectably spurred a considerable replicative exhaustion in MSCs; however, MSCs senescence could not be reversed by HDL preconditioning, which indicated that the effectiveness of HDL on the MSCs therapeutical potential in vivo was independent on the influence in cellular aging, while mainly through enhancement in cellular anti-apoptotic property. Indeed, the elucidation of this mechanism is especially critical for physicians engaged in cell-based therapy, whom must be sure that MSCs are devoid of chromosome alterations and that there are no signs of cellular senescence.

The clinical significance of our results is the possible benefit of HDL in patients with myocardial infarction in terms of improving the survival of transplanted MSCs. Elevation of HDL levels in patients, at high risk of cardiovascular disease may also be of vital clinical importance in preventing 
cardiovascular events. However, we did not identify the specific components of HDL that were responsible for its anti-oxidant and anti-apoptotic effects in the present study, for HDL is a lipoprotein, containing HDL2 and HDL3, with a density ranged from 1.063 to $1.210 \mathrm{~g} / \mathrm{mL}$ [28]. This will be the subject of future research, along with an investigation of other potential effects of HDL on MSCs (such as promotion of secretion); that may contribute to the restoration of cardiac function in vivo.

\section{Experimental Section}

\subsection{Isolation and Culture of MSCs}

All animal procedures were undertaken in accordance with the Guidelines for the Care and Use of Laboratory Animals, published by the National Academy Press (NIH Publication No. 85-23, Revised 1996). The experiments were approved by the Animal Care and Use Committee of Zhongshan Hospital, Fudan University.

MSCs were isolated from four-week-old Sprague-Dawley (SD) rats weighing 100 to $120 \mathrm{~g}$ by flushing femurs and tibias with Dulbecco's modified Eagle's medium (DMEM; GIBCO), 10\% Fetal Bovine Serum (FBS; GIBCO) and penicillin/streptomycin. The bone marrow (BM) solution was cultured at $37{ }^{\circ} \mathrm{C}$ in an atmosphere of $5 \% \mathrm{CO}_{2}$. The culture medium was changed every 3-4 days. Non-adherent hematopoietic cells were removed during this process, and the adherent, spindle-shaped MSCs were cultured and expanded. Passage 4 cells were used for subsequent experiments.

\subsection{Adenoviral Transduction and Labeling of MSCs}

An adenoviral vector carrying a green fluorescent protein (GFP) (GeneChem) for cell transduction was used to establish and identify a stable population of MSCs. Transduction was facilitated by transfecting Passage 4 MSCs with purified adenovirus cells that had been exposed to $7 \mu \mathrm{g} / \mathrm{mL}$ polybrene. The transfected cells were incubated for $24 \mathrm{~h}$ at $37{ }^{\circ} \mathrm{C}$ with $5 \% \mathrm{CO}_{2}$. The medium was removed, replaced with fresh medium and incubated for a further $24 \mathrm{~h}$. Cells were then sorted by flow cytometry for GFP to ensure that a homogenous population of $\mathrm{GFP}^{+}$MSCs was obtained (data were not shown).

\subsection{In vitro Exposure to $\mathrm{H}_{2} \mathrm{O}_{2}$ and $\mathrm{HDL}$}

MSCs were incubated for $6 \mathrm{~h}$ with DMEM supplemented with $1 \%$ FBS prior to experimental interventions. The starved MSCs were then respectively exposed to $\mathrm{H}_{2} \mathrm{O}_{2}(0$ to $500 \mu \mathrm{M})$ or $\mathrm{HDL}(0$ to $200 \mu \mathrm{g} / \mathrm{mL}$; Merck) for $24 \mathrm{~h}$. The experiments were undertaken in four groups: a control group; a HDL group (MSCs incubated with HDL $100 \mu \mathrm{g} / \mathrm{mL}$ for $24 \mathrm{~h}$ ); a $\mathrm{H}_{2} \mathrm{O}_{2}$ group (incubation with $400 \mu \mathrm{M} \mathrm{H}_{2} \mathrm{O}_{2}$ for $24 \mathrm{~h}$ ); a $\mathrm{HDL}+\mathrm{H}_{2} \mathrm{O}_{2}$ group (pre-incubation with $\mathrm{HDL} 100 \mu \mathrm{g} / \mathrm{mL}$ for $24 \mathrm{~h}$, followed by 24-h exposure to $400 \mu \mathrm{M} \mathrm{H}_{2} \mathrm{O}_{2}$ ). For inhibitor experiments, three additional groups were set as follows: MSCs were pre-incubated with PI3K inhibitor (LY294002, $25 \mu \mathrm{M}$ ) or vehicle (DMSO) for $1 \mathrm{~h}$, and then successively treated with $\mathrm{HDL}$ and $\mathrm{H}_{2} \mathrm{O}_{2}$ as above; the third group was pre-cultured with LY294002 alone. The concentrations of HDL, $\mathrm{H}_{2} \mathrm{O}_{2}$ and LY294002 used in these experiments were determined from pilot studies and based on similar methods described in the literature $[9,19,29]$. 


\subsection{MSC Viability Assay}

MSC viability was assessed using a 3-(4,5-dimethylthiazol-2-yl)-5-(3-carboxymethoxyphenyl)-2(4-sulfophenyl)-2H-tetrazolium, inner salt (MTS) assay. Cells were cultured in 24-well plates and treated according to the protocol. After 24 h, Cell Titer $96^{\circledR}$ Aqueous One Solution Reagent (Promega) was added to each well according to the manufacturer's instructions. Cell viability was evaluated after 2-h incubation with this reagent, by testing absorbance at $490 \mathrm{~nm}$ using a plate reader.

\subsection{TUNEL (Terminal Dexynucleotidyl Transferase-Mediated dUTP Nick end Labeling) Assay}

Cell apoptosis was investigated using an In Situ Cell Death Detection kit (Roche). In brief, MSCs were fixed in $3.7 \%$ buffered formaldehyde, pretreated with $3.0 \% \mathrm{H}_{2} \mathrm{O}_{2}$ and exposed to TdT enzyme at $37^{\circ} \mathrm{C}$ for $1 \mathrm{~h}$. The cells were then incubated with digoxigenin-conjugated nucleotide substrate at $37^{\circ} \mathrm{C}$ for $30 \mathrm{~min}$. Nuclei exhibiting DNA fragmentation were identified after staining with 3,3-diamino benzidine (DAB) for $5 \mathrm{~min}$.

The MSCs were counterstained with hematoxylin and viewed by light microscopy. Five fields at high magnification $(\times 200)$ were randomly chosen to assess the apoptosis index, which was calculated as a percentage of labeled cells to total nuclei.

\subsection{Caspase-3 Activity Assay}

Caspase-3 activity was determined in MSC lysates $(200 \mu \mathrm{g})$ using Caspase-3/CPP32 Fluorometric Assay kit (BioVision). The fluorogenic CPP32/caspase-3 substrate was labeled with the fluorochrome 7-amino-4-methyl coumarin. In this assay, the amount of fluorescence produced upon cleavage was proportional to the amount of caspase- 3 activity present in the sample.

\subsection{Senescence-Associated $\beta$-Galactosidase Staining}

MSCs cultured in six-well plates were rinsed with phosphate-buffered saline (PBS), fixed and then incubated with freshly prepared senescence-associated $\beta$-Galactosidase (SA- $\beta$-Gal) staining solution (Beyotime, China) at $37{ }^{\circ} \mathrm{C}$ overnight. Five fields at high magnification $(\times 200)$ were randomly chosen to count the number of blue cells (SA- $\beta$-Gal positive cells). At least 500 cells in each group were examined and the percentages of blue cells presented.

\subsection{Western Blot Analysis}

MSCs from each group were rinsed with cold PBS and lysed using RIPA buffer containing $1 \mathrm{mM}$ phenylmethanesulfonylfluoride on ice for $30 \mathrm{~min}$. The lysates were transferred to $1.5 \mathrm{~mL}$ Eppendorf tubes and centrifuged at $4{ }^{\circ} \mathrm{C}$ and $15,000 \mathrm{rpm}$ for $30 \mathrm{~min}$. The protein component was separated by $12 \%$ SDS-PAGE and then transferred to polyvinylidene fluoride membranes (Millipore). The membranes were blocked in 5\% skimmed milk for $2 \mathrm{~h}$ at room temperature, and were incubated overnight at $4{ }^{\circ} \mathrm{C}$ with anti-phospho-Akt (Cell Signaling), anti-Akt (Cell Signaling), anti-p16 ${ }^{\text {INK4a }}$. Following a $30 \mathrm{~min}$ wash, the membranes were incubated for $1 \mathrm{~h}$ with a secondary antibody conjugated to horseradish peroxidase-conjugated IgG (Jackson). Protein expression was determined 
using an enhanced chemiluminescence system and quantified by densitometry (Image System; Bio-Rad).

\subsection{Measurement of ROS}

The production of intracellular ROS was measured using an oxidation-sensitive fluorescent dihydroethidium (DHE) probe (Vigorous). The assay was based on the principle that DHE crosses cell membranes and is rapidly oxidized in the presence of ROS resulting in the formation of a highly fluorescent form of oxidative ethidium.

In this assay MSCs were washed three-times with PBS and incubated with $10 \mu \mathrm{M}$ DHE in phenol-red-free MEM medium (Invitrogen) at $37{ }^{\circ} \mathrm{C}$ in the dark. After 15 min incubation, the cells were rinsed and the medium was replaced. The fluorescence level, as an indicator of ROS production, was detected using fluorescence microscopy. The excitation and emission filters were $488 \mathrm{~nm}$ and $590 \mathrm{~nm}$, respectively.

\subsection{Myocardial Infarction and MSCs Transplantation}

The MI model was developed in SD rats $(220 \pm 30 \mathrm{~g})$, as previously described [22]. MSCs $\left(1 \times 10^{6}\right.$ in $100 \mu \mathrm{L}$, derived from male rats) (MSCs group) or MSCs preconditioned with HDL (HDL-MSCs group) were intramyocardially injected into female rats $10 \mathrm{~min}$ after ligation-induced infarction. The MSCs were injected into 3 to 5 injection sites into the anterior aspect of the viable myocardium that bordered the area of infarction. For the experiments concerning cardiac remodeling, two additional groups were set as follows: rats received intramyocardial injection of $100 \mu \mathrm{L}$ of PBS without MSCs (PBS group) or received thoracotomy only but were not ligated (Sham group).

\subsection{Tracking of the GFP ${ }^{+}$MSCs Injected in MI Hearts}

To observe the donor MSCs survival in vivo, rats were sacrificed four days after cell implantation. Hearts were harvested and sliced transversally above the ligation suture. Tissue fixation was minimized to reduce autofluorescence. The sample was embedded at optimum cutting temperature and cut by a cryostat from the base (above the ligation) towards the apex until the ligation suture was reached. Beginning at this point, $10 \mu \mathrm{m}$ sections were collected throughout the entire lesion. The sections were stained using DAPI (4,6-diamidino-2-phenylindole), and the number of $\mathrm{GFP}^{+} \mathrm{MSCs}$ was estimated under fluorescent microscopy at a magnification of $\times 200$.

Three photomicrographs were taken from the infarct border zone of each section. Six sections were selected for counting, giving a total of 18 high power fields per rat. The numbers of $\mathrm{GFP}^{+} \mathrm{MSCs}$ were counted and averaged.

\subsection{Real-Time Polymerase Chain Reaction}

Real-time polymerase chain reaction (PCR) was performed for quantification of the male sry DNA levels on Day 4 after cell transplantation. Rats were sacrificed and hearts were excised, frozen in liquid nitrogen and powdered. DNA purification was performed using Genomic DNA Isolation kit (Qiagen). The concentration of the purified DNA was determined by spectrophotometry. Real-time PCR was 
performed using Takara SYBR Premix Ex TaqTM in a Bio-Rad iQ5 optical module. Primers for amplification of rat $\mathrm{Y}$ chromosome sry and $\beta$-actin genes were synthesized (Invitrogen) and were listed as follows: sry, forward, 5'-GAG GCA CAA GTT GGC TCA ACA-3'; reverse, 5'-CTC CTG CAA AAA GGG CCT TT-3'. $\beta$-actin, forward, 5'-CCA TTG AAC ACG GCA TTG-3'; reverse, 5'-TAC GAC CAG AGG CAT ACA-3'. The cycling conditions were: $30 \mathrm{~s}$ at $95{ }^{\circ} \mathrm{C}$, followed by 40 cycles of $5 \mathrm{~s}$ at $95{ }^{\circ} \mathrm{C}, 30 \mathrm{~s}$ at $59.5^{\circ} \mathrm{C}, 30 \mathrm{~s}$ at $72{ }^{\circ} \mathrm{C}$. Melting curves were acquired at the end of the reaction by gradually raising the temperature by $1{ }^{\circ} \mathrm{C} / \mathrm{min}$ from $59.5^{\circ} \mathrm{C}$ to $95{ }^{\circ} \mathrm{C}$ over a time period of $35 \mathrm{~min}$.

\subsection{Echocardiography}

Cardiac remodeling and left ventricular function were assessed by transthoracic echocardiography 4 weeks after MI, using a Vevo 770 high-resolution imaging system (Visual Sonics) with a 17.5-MHz probe. After the induction of light general anesthesia, hearts were imaged in two dimensional and M-modes. The recordings were obtained in the para-sternal long-axis view at the level of the greatest LV diameter. The LV internal end-diastolic diameter (LVIDd) and LV internal end-systolic diameter (LVIDs) were measured from M-mode recordings according to the leading-edge method. All echocardiographic measurements were averaged from at least five separate cardiac cycles.

\subsection{Statistical Analysis}

Statistical analysis was undertaken using SPSS version 16.0. All data were expressed as means and standard errors (SE). Between-group of differences was analyzed using Student's $t$-test. Comparisons between more than two groups were performed using one-way analysis of variance (ANOVA) with Bonferroni's correction. Values of $p<0.05$ were considered statistically significant.

\section{Conclusions}

In summary, we demonstrated that $\mathrm{HDL}$ protected $\mathrm{MSC}$ from $\mathrm{H}_{2} \mathrm{O}_{2}$-induced apoptosis by activation of the PI3K/Akt pathway and down-regulation of ROS generation; and that preconditioning with HDL promoted MSCs survival after cell transplantation, thereby preserving cardiac function. This observation provides an experimental basis for improving the prognosis of patients with myocardial infarction through elevation of HDL levels. The HDL-based therapy may hold the promise of reducing the incidences of such left ventricular remodeling and heart failure after myocardial damage.

\section{Acknowledgments}

This work was supported by grants from the National Natural Science Foundation of China (Project No. 81100145, No. 81000043 and No. 81100075), Shuguang Project of Shanghai (Project No. 08SG03), Research Fund for the Doctoral Program of Higher Education of China (Project No. 20100071120072) and the National Basic Research Program of China (973 Program, 2012CB518605).

\section{Conflict of Interest}

The authors declare no conflict of interest. 


\section{References}

1. Huang, J.; Zhang, Z.; Guo, J.; Ni, A.; Deb, A.; Zhang, L.; Mirotsou, M.; Pratt, R.E.; Dzau, V.J. Genetic Modification of Mesenchymal Stem Cells Overexpressing CCR1 Increases Cell Viability, Migration, Engraftment, and Capillary Density in the Injured Myocardium. Circ. Res. 2010, 106, 1753-1762.

2. Wen, Z.Z.; Zheng, S.X.; Zhou, C.Q.; Yuan, W.L.; Wang, J.F.; Wang, T. Bone marrow mesenchymal stem cells for post-myocardial infarction cardiac repair: MicroRNAs as novel regulators. J. Cell. Mol. Med. 2012, 16, 657-671.

3. Luo, Y.; Wang, Y.; Poynter, J.A.; Manukyan, M.C.; Herrmann, J.L.; Abarbanell, A.M.; Weil, B.R.; Meldrum, D.R. Pretreating mesenchymal stem cells with interleukin-1 beta and transforming growth factor-beta synergistically increases vascular endothelial growth factor production and improves mesenchymal stem cell-mediated myocardial protection after acute ischemia. Surgery 2012, 151, 353-363.

4. Wei, H.; Li, Z.; Hu, S.; Chen, X.; Cong, X. Apoptosis of Mesenchymal Stem Cells Induced by Hydrogen Peroxide Concerns Both Endoplasmic Reticulum Stress and Mitochondrial Death Pathway Through Regulation of Calspases, p38 and JNK. J. Cell. Biochem. 2010, 111, 967-978.

5. Wang, X.; Zhao, T.; Huang, W.; Wang, T.; Qian, J.; Xu, M.; Kranias, E.G.; Wang, Y.; Fan, G.-C. Hsp20-Engineered Mesenchymal Stem Cells Are Resistant to Oxidative Stress via Enhanced Activation of Akt and Increased Secretion of Growth Factors. Stem Cells 2009, 27, 3021-3031.

6. Zanichelli, F.; Capasso, S.; di Bernardo, G.; Cipollaro, M.; Pagnotta, E.; Carteni, M.; Casale, F.; Iori, R.; Giordano, A.; Galderisi, U. Low concentrations of isothiocyanates protect mesenchymal stem cells from oxidative injuries, while high concentrations exacerbate DNA damage. Apoptosis 2012, 17, 964-974.

7. Duffy, D.; Holmes, D.N.; Roe, M.T.; Peterson, E.D. The impact of high-density lipoprotein cholesterol levels on long-term outcomes after non-ST-elevation myocardial infarction. Am. Heart J. 2012, 163, 705-713.

8. Navab, M.; Reddy, S.T.; van Lenten, B.J.; Fogelman, A.M. HDL and cardiovascular disease: Atherogenic and atheroprotective mechanisms. Nat. Rev. Cardiol. 2011, 8, 222-232.

9. Lin, L.; Gong, H.; Ge, J.; Jiang, G.; Zhou, N.; Li, L.; Ye, Y.; Zhang, G.; Ge, J.; Zou, Y. High density lipoprotein downregulates angiotensin II type 1 receptor and inhibits angiotensin II-induced cardiac hypertrophy. Biochem. Biophys. Res. Commun. 2011, 404, 28-33.

10. Nicholls, S.J.; Dusting, G.J.; Cutri, B.; Bao, S.; Drummond, G.R.; Rye, K.A.; Barter, P.J. Reconstituted high-density lipoproteins inhibit the acute pro-oxidant and proinflammatory vascular changes induced by a periarterial collar in normocholesterolemic rabbits. Circulation 2005, 111, 1543-1550.

11. De Souza, J.A.; Vindis, C.; Negre-Salvayre, A.; Rye, K.-A.; Couturier, M.; Therond, P.; Chantepie, S.; Salvayre, R.; Chapman, M.J.; Kontush, A. Small, dense HDL 3 particles attenuate apoptosis in endothelial cells: pivotal role of apolipoprotein A-I. J. Cell. Mol. Med. 2010, 14, 608-620. 
12. Sumi, M.; Sata, M.; Miura, S.-I.; Rye, K.-A.; Toya, N.; Kanaoka, Y.; Yanaga, K.; Ohki, T.; Saku, K.; Nagai, R. Reconstituted high-density lipoprotein stimulates differentiation of endothelial progenitor cells and enhances ischemia-induced angiogenesis. Arterioscler. Thromb. Vasc. Biol. 2007, 27, 813-818.

13. Ng, K.-M.; Lee, Y.-K.; Lai, W.-H.; Chan, Y.-C.; Fung, M.-L.; Tse, H.-F.; Siu, C.-W. Exogenous Expression of Human apoA-I Enhances Cardiac Differentiation of Pluripotent Stem Cells. PLoS One 2011, 6, e19787.

14. Yvan-Charvet, L.; Pagler, T.; Gautier, E.L.; Avagyan, S.; Siry, R.L.; Han, S.; Welch, C.L.; Wang, N.; Randolph, G.J.; Snoeck, H.W.; et al. ATP-Binding Cassette Transporters and HDL Suppress Hematopoietic Stem Cell Proliferation. Science 2010, 328, 1689-1693.

15. Wang, B.; Shravah, J.; Luo, H.; Raedschelders, K.; Chen, D.D.Y.; Ansley, D.M. Propofol protects against hydrogen peroxide-induced injury in cardiac H9c2 cells via Akt activation and Bcl-2 up-regulation. Biochem. Biophys. Res. Commun. 2009, 389, 105-111.

16. Brandl, A.; Meyer, M.; Bechmann, V.; Nerlich, M.; Angele, P. Oxidative stress induces senescence in human mesenchymal stem cells. Exp. Cell. Res. 2011, 317, 1541-1547.

17. Di Bernardo, G.; Alessio, N.; Dell'Aversana, C.; Casale, F.; Teti, D.; Cipollaro, M.; Altucci, L.; Galderisi, U. Impact of Histone Deacetylase Inhibitors SAHA and MS-275 on DNA Repair Pathways in Human Mesenchymal Stem Cells. J. Cell. Physiol. 2010, 225, 537-544.

18. Zhu, Z.; Sun, H.; Ma, G.; Wang, Z.; Li, E.; Liu, Y.; Liu, Y. Bufalin Induces Lung Cancer Cell Apoptosis via the Inhibition of PI3K/Akt Pathway. Int. J. Mol. Sci. 2012, 13, 2025-2035.

19. Li, S.; Bian, H.; Liu, Z.; Wang, Y.; Dai, J.; He, W.; Liao, X.; Liu, R.; Luo, J. Chlorogenic acid protects MSCs against oxidative stress by altering FOXO family genes and activating intrinsic pathway. Eur. J. Pharmacol. 2012, 674, 65-72.

20. Tam, D.N.N.; Son, Y.O.; Lim, S.S.; Shi, X.L.; Kim, J.G.; Heo, J.S.; Choe, Y.; Jeon, Y.M.; Lee, J.C. Sodium fluoride induces apoptosis in mouse embryonic stem cells through ROS-dependent and caspase- and JNK-mediated pathways. Toxicol. Appl. Pharmacol. 2012, 259, 329-337.

21. Kiya, Y.; Miura, S.-I.; Imaizumi, S.; Uehara, Y.; Matsuo, Y.; Abe, S.; Jimi, S.; Urata, H.; Rye, K.-A.; Saku, K. Reconstituted high-density lipoprotein attenuates postinfarction left ventricular remodeling in rats. Atherosclerosis 2009, 203, 137-144.

22. Xie, X.X.; Sun, A.J.; Zhu, W.Q.; Huang, Z.Y.; Hu, X.Y.; Jia, J.G.; Zou, Y.Z.; Ge, J.B. Transplantation of Mesenchymal Stem Cells Preconditioned with Hydrogen Sulfide Enhances Repair of Myocardial Infarction in Rats. Tohoku J. Exp. Med. 2012, 226, 29-36.

23. Mangi, A.A.; Noiseux, N.; Kong, D.L.; He, H.M.; Rezvani, M.; Ingwall, J.S.; Dzau, V.J. Mesenchymal stem cells modified with Akt prevent remodeling and restore performance of infarcted hearts. Nat. Med. 2003, 9, 1195-1201.

24. Suzuki, Y.; Kim, H.W.; Ashraf, M.; Haider, H.K. Diazoxide potentiates mesenchymal stem cell survival via NF- $\kappa$ B-dependent miR-146a expression by targeting Fas. Am. J. Physiol. Heart Circul. Physiol. 2010, 299, H1077-H1082.

25. Rossoni, G.; Gomaraschi, M.; Berti, F.; Sirtori, C.R.; Franceschini, G.; Calabresi, L. Synthetic high-density lipoproteins exert cardioprotective effects in myocardial ischemia/reperfusion injury. J. Pharmacol. Exp. Ther. 2004, 308, 79-84. 
26. Strandberg, T.E.; Saijonmaa, O.; Fyhrquist, F.; Tilvis, R.S.; Strandberg, A.Y.; Miettinen, T.A.; Pitkala, K.H.; Salomaa, V. Telomere length in old age and cholesterol across the life course. J. Am.Geriatr. Soc. 2011, 59, 1979-1981.

27. Barzilai, N.; Atzmon, G.; Schechter, C.; Schaefer, E.J.; Cupples, A.L.; Lipton, R.; Cheng, S.; Shuldiner, A.R. Unique lipoprotein phenotype and genotype associated with exceptional longevity. J. Am. Med. Assoc. 2003, 290, 2030-2040.

28. Tian, L.; Fu, M. The relationship between high density lipoprotein subclass profile and apolipoprotein concentrations. J. Endocrinol. Invest. 2011, 34, 461-472.

29. Terasaka, N.; Wang, N.; Yvan-Charvet, L.; Tall, A.R. High-density lipoprotein protects macrophages from oxidized low-density lipoprotein-induced apoptosis by promoting efflux of 7-ketocholesterol via ABCG1. Proc. Natl. Acad. Sci. USA 2007, 104, 15093-15098.

(C) 2012 by the authors; licensee MDPI, Basel, Switzerland. This article is an open access article distributed under the terms and conditions of the Creative Commons Attribution license (http://creativecommons.org/licenses/by/3.0/). 